Relations industrielles

Industrial Relations

\title{
Le commerce est un service
}

Volume 9, numéro 1, décembre 1953

URI : https://id.erudit.org/iderudit/1022918ar

DOI : https://doi.org/10.7202/1022918ar

Aller au sommaire du numéro

\section{Éditeur(s)}

Département des relations industrielles de l’Université Laval

\section{ISSN}

0034-379X (imprimé)

1703-8138 (numérique)

Découvrir la revue

\section{Citer ce document}

(1953). Le commerce est un service. Relations industrielles / Industrial Relations, 9(1), 78-79. https://doi.org/10.7202/1022918ar
Résumé de l'article

Le Saint-Père a adressé l'allocution suivante, en français, aux participants du XXVIIe Congrès de la Société internationale pour renseignement commercial.
Tous droits réservés (C Département des relations industrielles de l’Université Laval, 1953
Ce document est protégé par la loi sur le droit d'auteur. L’utilisation des services d'Érudit (y compris la reproduction) est assujettie à sa politique d'utilisation que vous pouvez consulter en ligne.

https://apropos.erudit.org/fr/usagers/politique-dutilisation/ 
et connaît mieux que d'autre la condition humaine. Sa doctrine sociale reflète très exactement cette position centrale et s'efforce de faire respecter l'ordre des exigences de l'homme to'al, corps et âme, individu et membre de la société, enfant des hommes et fils de Dieu. C'est pourquoi les principes chrétiens sont les plus sûrs garants d'une évolution normale et heureuse de l'humanité.

Nous avons loué tantôt votre souci de répondre pleinement à votre rôle social. Votre siluation au sein des entreprises, où vous constituez le lien entre la direction générale et les agents d'exécution, réclame de vous non seulement des aptitudes professionnelles, mais un sens profondément humain. Vous avez à diriger des personnes intelligentes et libres. Si vous vous efforcez de garder devant les yeux la vue de l'homme totale et compréhensive, dont Nous venons de parler vous r'aurez pas de peine à vous rendre comp'e que les problèmes personels qui engagent votre vie et votre destinée, ceux qui touchent aux couches les plus intimes de votre esprit et de votre coeur, se posent avec autant d'acuité, bien que d'une manière moins réfléchie, pour le plus humble de vos subordonnés. Vous aimez qu'on vous laisse la liberté de prendre des ini'iatives; vous désirez percevoir le but poursuivi et enregistrer au fur et à mesure les étapes qui vous en rapprochent, vous souhaitez déborder le cadre purement professionnel, pour développer votre personnalité tout entière: tout cela est bon et légitime. Il est donc souhaitable que le travailleur le plus modeste $\mathrm{y}$ participe progressivement. Après l'avoir traité trop longtemps comme un outil de produc'ion, corvéable à merci, on s'est préoccupé des conditions matérielles de son existence. On reconnaît à présent qu'il serait bien insuffisant d'en rester là. Puisque le travail est pour tout homme une nécessité, il faut que les occupations professionnelles ne briment pas ses sentiments les plus naturels et les plus spontanés, mais respectent pleinement sa dignité. C'est dire qu'il ne peut suffire de voir en lui un producteur de biens, mais qu'il faut le traiter comme un être spiri'uel que son travail doit ennoblir et qui attend de ses chefs plus encore que de ses égaux, l'intelligence de ses besoins et une sympathie vraiment fraternelle.

\section{Le commerce est un service}

Le Saint-Père a adressé l'allocution suivante, en francais, aux participants du XXVIle Congrès de la Société in'ernationale pour l'enseignement commercial ${ }^{1}$ :

Nous vous souhaitons la bienvenue chez Nous et, de tout coeur, Nous saluons en vous les représentants d'une profession honorable, celle du commerçant.

Les relations entre l'Eglise et le commerçant sont assurément aussi vieilles que l'Eglise elle-même. Les rou'es, sur lesquelles les premiers messagers de 'Evangile, les apôtres, partirent à la conquête du monde, celles que parcouru! saint Paul daris les voyages que l'on retrace si volontiers d'après les Actes des Apôtres, n'étaient pas seulement les routes des légions et des fonctionnaires romains. mais aussi celles du marchand et du commerce mondial. Les choses en sont restées comme aux origines de l'Eglise; ainsi en était-il au XIIIe siècle sur les routes qui traversaient l'empire gigantesque de Gengis Khan et de ses fils; de mème au XVIe, quand François-Xavier, le hardi missionnaire, s'aventurait avec le commerçant audacieux sur les voies maritimes de l'Asie orientale jusqu'aux côtes du Japon et aux portes de la Chine; ainsi de nos jours encore sur le continen ${ }^{+}$noir: le pionnier du commerce mondial et le pionnier de la foi catholique se sont toujours rencontrés sur les mêmes chemins. Leurs mobiles pouvaient être très différents, mais l'esprit d'universalité, la conviction de l'égalité et de l'uni'é des hommes sont commun: à l'Eglise et' au marchand. L'histoire du commerce, surtout des foires, en fournit un précieux témoignage.

(1) D'après l'Osservatore Romano du 29 août 1953. 
Ce qui a mis l'Eglise en relation étroite avec la classe des commerçants, ce fut son souci permanent de la haute valeur morale de cette profession. Vous penserez peut-ètre, en entendant ces mots, à l'histoire de la législation contre l'usure, et vous le pouvez, certes. Quelles que soient les critiques adressées à la position de l'Eglise, un point ne peut ètre passé sous silence: il s'agissait ici d'assurer une véritable activité conmerciale, afin de procurer le mieux possible aux hommes les biens et les services matériels. Qu une prestation réelle réponde au gain du marchand voilà le souci de l'Eglise et de ses moralistes, et non, comme on l'a affirmé à tort, une aversion en quelque sorte innée envers le commerce.

Cette préoccupation n'est-elle pas opportune de nos jours encore? La profession de négociant et l'estime qu'on lui porte ne dépendent-elles pas du fait que Nous pourrions formuler ainsi: il rend un vrai service à un vrai client? Un service véritable donc, à un vrai client, c'est-à-dire à un client possédant un pouvoir d'achat réel, qu'il engage pour des besoins réels. Les tentations contre ce principe de morale professionnelle sont aujourd'hui particulièrement fortes: pouvoir d'achat falsifié, besoins fomentés artificiellement, marchés devenus démesurés, étalons monétaires instables, désordre dans les relations entre l'Etat, la politique et l'économie, font que l'attrait de la spéculation malsaine menace les fondements du commerce. Le service véritable au client véritable en souffre; et la profession du commerçant n'est pas la dernière à subir le préjudice; elle est atteinte dans ses bases morales et perd l'estime des gens.

Puisse donc la pensée d'un vrai service à rendre à de vrais clients pénétrer vos efforts de formation. Votre profession exige certes aujourd'hui plus que jamais des connaissances économiques, techniques, linguistiques, et' de nombreuses qualités: sens de l'organisation, zèle, énergie et courage pour oser. Mais plus importante encore est l'exigence fondamentale: une haute conception, appuyée sur les principes moraux, de la profession de négociant et de sa fonction dans l'économie nationale. Aussi la formation commerciale ne peut être, aujourd'hui moins que jamais, un apprentissage technique unilatéral; elle doit tenir le regard ouvert sur l'ensemble des valeurs humaines et se proposer avant tout comme but d'amener à maturité des caractères doués de solidité morale.

Voilà ce que Nous croyions devoir vous dire et ce que Nous vous souhaitons de tout coeur. Daigne le Dieu tout-puissant vous bénir tous personnellement et toute votre profession.

\section{Méthodes pratiques d'accroissement de la productivité *}

\section{Principes généraux d'utilisation des systèmes de rémunération au rendement INTRODUCTION}

1-Il est généralement admis qu'une augmentation constante de la productivité du travail est la condition essentielle pour assurer un niveau de vie plus élevé à toutes les couches de la population et notamment aux travailleurs salariés.

2-Cette conception a donné une nouvelle importance aux systèmes de salaires au rendement. Dans la mesure où de tels systèmes de salaires peuvent être efficacement appliqués, ils contribueront à assurer une production accrue, génératrice de bien-être général.

(*) Conclusions adoptées par la réunion d'experts en matière de systèmes de rénumération au rendement.

(*) Extrait du document communiqué à la Conférence internationale du Travail (36ième session) comme supplément au Rapport du Directeur général. 